\title{
High Temperature Annealing of Ion-Plasma Nanostructured Coatings Based on $\mathrm{AlN}-\mathrm{TiB}_{2}\left(\mathrm{TiSi}_{2}\right)$
}

\author{
A.D. Pogrebnjak ${ }^{a, *}$, G. Abadias ${ }^{b}$, O.V. Bondar ${ }^{a}$, O.V. Sobol ${ }^{c}$, V.M. Beresnev ${ }^{d}$, \\ A.V. PshyK ${ }^{a}$, A.A. Demianenko ${ }^{a}$, K.O. Belovol ${ }^{a}$, D.A. Kolesnikov ${ }^{e}$ And H. Komsta ${ }^{f}$ \\ ${ }^{a}$ Sumy State University, Rymskogo-Korsakova 2, Sumy, 40007, Ukraine \\ ${ }^{b}$ Institute P', Université de Poitiers-CNRS-ENSMA, SP2MI, \\ TéléportÂ 2, F86962 Chasseneuil-Futuroscope CEDEX, France, France \\ ${ }^{c}$ National Science Center, Kharkov Institute of Physics and Technology, \\ Akademicheskaya 1, Kharkiv, 61108, Ukraine \\ ${ }^{d}$ Kharkiv National University, maj. Nezalezhnosti 4, Kharkiv, 61022, Ukraine \\ ${ }^{e}$ Belgorod State University, Pobedy 85, Belgorod, 308015, Russia \\ ${ }^{f}$ Institute of Transport, Combustion Engines and Ecology, Lublin University of Technology, \\ Nadbystrzycka 36, 20-618 Lublin, Poland
}

\begin{abstract}
The coatings investigated in this paper were deposited via the magnetron sputtering of $\mathrm{AlN}-\mathrm{TiB}_{2}-\mathrm{Ti}_{-}-\mathrm{Si}_{2}$ target in Ar atmosphere. The investigation of structural-phase composition, element composition, morphology and mechanical properties before and after annealing up to $1350{ }^{\circ} \mathrm{C}$ was carried out. The concentration of elements in the coating was changed after annealing at $900{ }^{\circ} \mathrm{C}$ and further annealing at $1350{ }^{\circ} \mathrm{C}$ (especially after annealing at $1350{ }^{\circ} \mathrm{C}$ ). The hardness of as-deposited coatings was $15 \mathrm{GPa}$, but after annealing at $1350^{\circ} \mathrm{C}$ the value of hardness increased up to $22 \div 23.5 \mathrm{GPa}$. The value of the viscoplastic index was 0.07 . All this provide high damping properties of the coating, and amorphous-like structure makes promising the use of these coatings as diffusion barriers in the form of independent elements, and as a contacting layer in multilayer wear resistant coatings.
\end{abstract}

DOI: 10.12693/APhysPolA.125.1284

PACS: 68.60.Dv, 68.37.-d, 62.20.-x

\section{Introduction}

It is well known [1-3] that it is possible to control the structure and substructure of produced materials by changing of ion-plasma deposited particles energy, which participate in formation of films. From the other side, it is possible to block the growth of grains of base phase by addition of one or several elements to a base material and thereby to form coatings with nanocrystalline or amorphous-like structure. It is necessary to study how to operate by grain size and crystallographic orientations of grains in the growing film in order to form nanocrystalline films and coatings. It can be achieved by several ways [4]: by changing of energy of sputtered particles of growing condensate; by penetration of addition elements into base material which bounds grains size growth; by deposition of multilayer films with nanoscale thickness; by formation of nanocomposite coatings. It can be achieved by several ways: by changing of energy of sputtered particles of growing condensate; by penetration of addition elements into base material which limits grains size growth; by deposition of multilayer films with nanoscale thickness; by formation of nanocomposite coatings.

*corresponding author; e-mail: alexp@i.ua
The basic parameters which can be used to control film structure are substrate temperature $T_{\mathrm{s}}$; the energy $E_{\text {bi }}$ which is transferred to growing film by bombarded ions and fast neutrals, as well as a quantity and type of addition elements [5, 6]. However, the other factors play a great role in formation of nanostructured films such as: intermiscibility or nonmiscibility of film components; ability of components to form solid solution or intermetallic compounds; enthalpy of alloy formation $\Delta H_{\mathrm{f}}$ (positive or negative).

The structure of a film depends greatly on different factors and their reciprocal combinations $[7,8]$. That is why investigation of phase composition, structure, physical-mechanical properties of multicomponent coatings which are composed of non-metallic matrix and nanostructured metallic components based on nitrides, carbides, borides and silicides are of great scientific interest.

The main aim of this work is to carry out comprehensive analysis of structure, phase composition, surface morphology and physical-mechanical properties of coatings which are obtained by magnetron sputtering of multicomponent target $\mathrm{AlN}-\mathrm{TiB}_{2}-\mathrm{TiSi}_{2}$.

\section{Experimental}

Polished steel (Fe, $18 \%-\mathrm{Ni}, 12 \%-\mathrm{Cr}, 10 \%-\mathrm{Ti})$ and monocrystalline silicon cylinders of $20 \mathrm{~mm}$ diameter and $3 \mathrm{~mm}$ highness were used as substrate materials. 
The high-temperature $\mathrm{AlN}-\mathrm{TiB}_{2}$ composite systems with addition of $\mathrm{TiSi}_{2}$ were used as sputtered material. The coatings investigated in this paper were deposited via the magnetron sputtering in Ar atmosphere.

Coating thickness, state of the coating-substrate interface were characterized using fracture fractography obtained by scanning electron microscope Quanta 600 and JEOL-7000F (Japan) operating at acceleration voltage $20 \mathrm{kV}$. The chemical composition and morphology were investigated using scanning electron microscopy (SEM) with microanalysis (EDS - energy disperse X-ray spectroscopy).

The X-ray diffraction (XRD) data were recorded in Bruker-8 Advance and DRON-4m apparatus using a $\mathrm{Cu} K_{\alpha}$ radiation.

Additionally, the analysis of surface topography was carried out by atomic force microscope NT-MDT (Russia). Si-cantilevers NSG10/W2C with hard current-conducting coating $\mathrm{W} 2 \mathrm{C}$ of the $30 \mathrm{~nm}$ thickness were used.

The mechanical characteristics of the coatings layers were measured by a Nanoindentor G200 (MTS Systems Corp., USA) tester with a trihedral Berkovich pyramid with the tip radius at the apex $20 \mathrm{~nm}$.

\section{Results and discussion}

Surface topography investigations of specimens with coating were carried out by scanning electronic microscope Quanta 600 D. Figure 1a represents SEM images of surface topography.

It is important to note that, in accordance to EDX analysis results, significant changes of elements concentration was observed after annealing at $900{ }^{\circ} \mathrm{C}$ and $1350{ }^{\circ} \mathrm{C}$ (Fig. $1 \mathrm{~b}$ and Table).

TABLE

Results of energy dispersive analysis of $\mathrm{AlN}-\mathrm{TiB}_{2}-$ $\mathrm{TiSi}_{2}$ coating before and after annealing under $900{ }^{\circ} \mathrm{C}$ and $1350{ }^{\circ} \mathrm{C}$.

\begin{tabular}{c|c|c|c}
\hline \multirow{2}{*}{ Element } & \multicolumn{3}{|c}{ Annealing temperature [at.\%] } \\
\cline { 2 - 4 } & As-deposited & $900^{\circ} \mathrm{C}$ & $1350{ }^{\circ} \mathrm{C}$ \\
\hline $\mathrm{B}$ & 30.25 & 33.92 & 5.45 \\
$\mathrm{C}$ & 4.92 & 2.93 & 15.44 \\
$\mathrm{~N}$ & 21.80 & 16.67 & 20.33 \\
$\mathrm{O}$ & 8.23 & 20.20 & 7.5 \\
$\mathrm{Al}$ & 14.18 & 9.80 & 1.7 \\
$\mathrm{Si}$ & 11.26 & 11.52 & 47.8 \\
$\mathrm{Ar}$ & 2.03 & 0.17 & - \\
$\mathrm{Ti}$ & 3.32 & 4.64 & 1.57 \\
$\mathrm{Mo}$ & - & 0.16 & - \\
$\mathrm{Re}$ & - & - & 0.22 \\
$\mathrm{sum}$ & 100.00 & 100.00 & 100.00
\end{tabular}

Figure 2a shows atomic force microscopy image of as-deposited coating surface where grain boundary and nanotopography appears. Profile of AFM image and statistical analysis of heights distribution provide additional

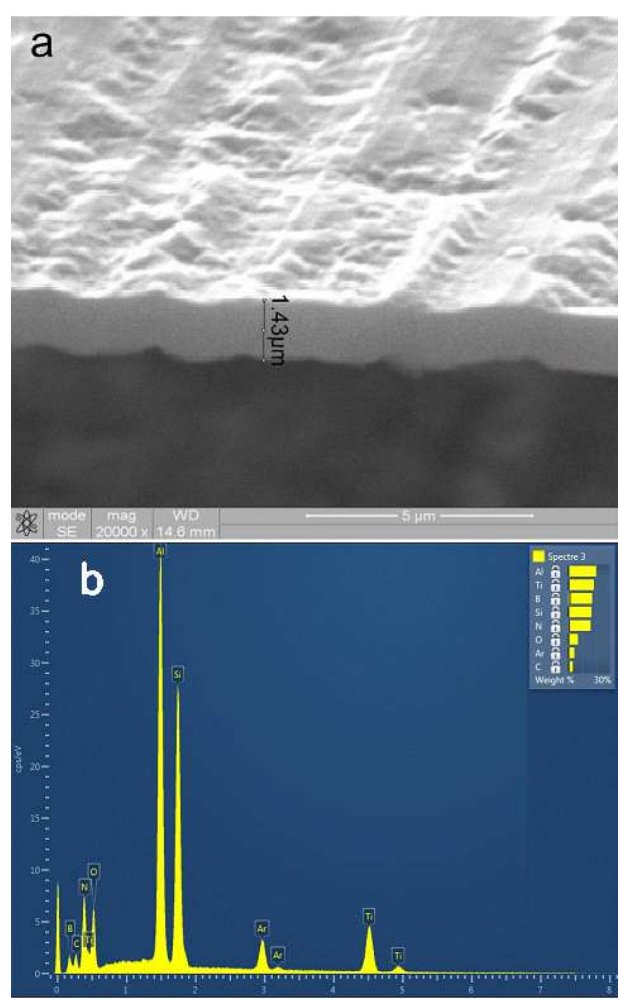

Fig. 1. Surface topography of $\mathrm{AlN}-\mathrm{TiB}_{2}-\mathrm{TiSi}_{2}$ coating: (a) fracture fractography, (b) the EDS data.

and more precise information about relief of the coatings. The statistical analysis showed that the most of asperities had heights in the range $15-20 \mathrm{~nm}$. The lateral dimensions of asperities at the bottom were $\approx 200 \mathrm{~nm}$, and the width of asperities at the half of height was approximately $70 \mathrm{~nm}$. It was established that roughness of the surface was varied from $30-35 \mathrm{~nm}$ to $70-90 \mathrm{~nm}$ after high temperature annealing.

At the numerous papers, which are devoted to investigation of results of energy influence on surface of condensed matter [9-15] the appearance of defect-deformation instability has been shown. It causes the realization of critical conditions for development of synergetic effect which leads to development of surface structures of topography.

In this work, the influence of energy particles, which are the part of multicomponent coating, on evolution of surface topography formation is characterized by processes of phase composition changing of near-surface layers, recrystallization and appearing of areas with reduced stresses.

Figure 3 shows two diffraction spectra of substrate with coating (1) and substrate without coating (2), and also the final spectrum obtained by subtraction from first spectrum the second spectrum, which corresponds to diffraction spectrum of coating. It was identified after obtaining the resultant diffraction spectrum that the spectrum has no sharp diffraction maximum from the 

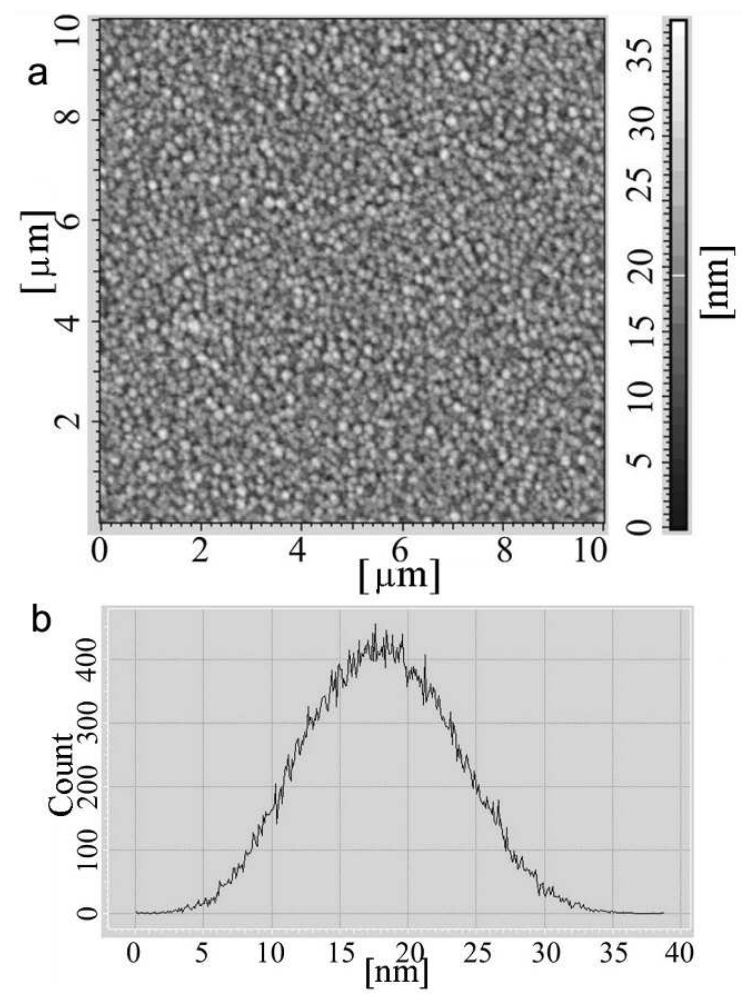

Fig. 2. Profile of AFM image of $\mathrm{AlN}-\mathrm{TiB}_{2}-\mathrm{TiSi}_{2}$ coating (a) and statistical analysis of heights distribution (b).

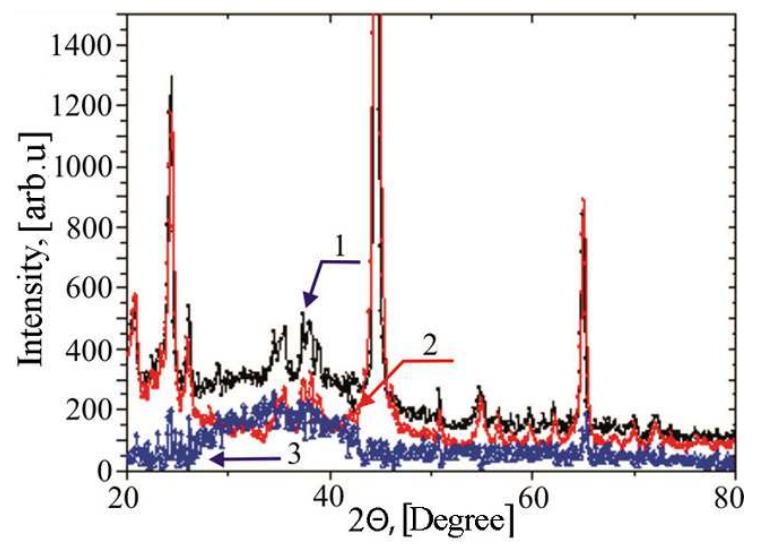

Fig. 3. Diffraction spectra taken for the coatings of AlN-TiB $2-\mathrm{TiSi}_{2}$ system: 1 - "coating-steel substrate", 2 - "steel substrate", 3 - resultant spectrum.

crystalline component, and also it has "halo-like" character.

The halo-like resultant curve (Fig. 4, arrows indicate the maxima of short-range ordering) indicates strong disordering of coating crystallites that corresponds to dimensions of the ordered area about $2 \mathrm{~nm}$ with the defined correlation length of the ordering $0.259 \mathrm{~nm}$ according to position of first maximum.

The hardness of as-deposited coatings was $15 \mathrm{GPa}$, but after the annealing under $1350^{\circ} \mathrm{C}$ the value of hardness

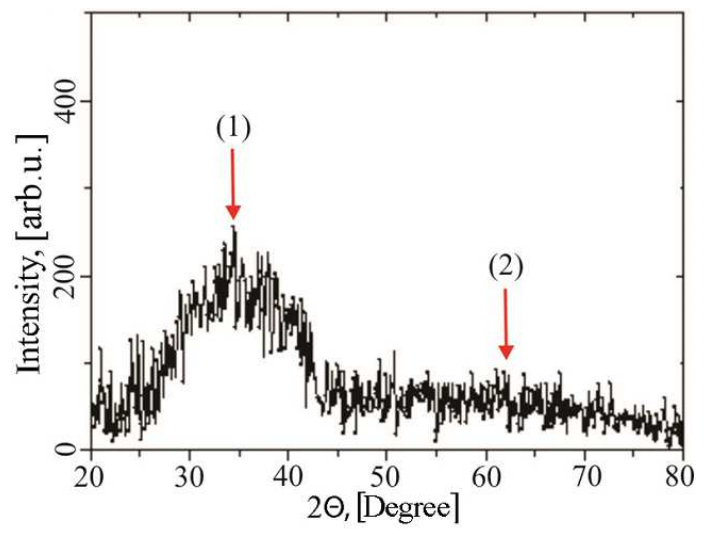

Fig. 4. The resultant diffraction pattern for AlN$\mathrm{TiB}_{2}-\mathrm{TiSi}_{2}$ coating.

was increased up to $(22 \div 23.5)$ GPa. The elastic modulus of as-deposited coating was equal to $E=206 \mathrm{GPa}$ and almost it was not changed and amounts to $E=218 \pm$ $6 \mathrm{GPa}$. The value of the viscoplastic index was 0.07 .

\section{Conclusions}

1. It was established that after deposition of ion-plasma coatings by magnetron sputtering of the AlN$\mathrm{TiB}_{2}-\mathrm{TiSi}_{2}$ target, amorphous-like structure was formed. The high dispersity is explained by high concentration of high amorphizing element - boron.

2. The statistical analysis showed that the most of asperities had peaks in the range $15-20 \mathrm{~nm}$. The lateral dimensions of asperities at the bottom were $\approx 200 \mathrm{~nm}$, and the width of asperities at the half of height was approximately $70 \mathrm{~nm}$. The roughness of the surface was enhanced after high temperature annealing.

3. The value of harness was enhanced from $H=$ $15.3 \mathrm{GPa}$ to $H=(22-23.5) \mathrm{GPa}$ after annealing at $1350^{\circ} \mathrm{C}$.

4. It is provided high damping properties of $\mathrm{AlN}-\mathrm{TiB}_{2}-\mathrm{TiSi}_{2}$ coatings, and amorphous-like structure makes promising the using of these coatings either like diffusion barrier or like self-contained element or like contacting layer in the multilayer wear-resistant coatings.

\section{References}

[1] A. Cavaleiro, J.Th.M.D. Hosson, Nanostructured Coatings, Springer, New York 2006.

[2] A.D. Pogrebnjak, A.G. Ponomarev, A.P. Shpak, Yu.A. Kunitskii, Phys. Usp. 55, 270 (2012).

[3] A.D. Pogrebnjak, A.P. Shpak, N.A. Azarenkov, V.M. Beresnev, Phys. Usp. 52, 29 (2009).

[4] N.A. Azarenkov, O.V. Sobol, A.D. Pogrebnjak, V.M. Beresnev, S.V. Lytovchenko, O.N. Ivanov, The Materials Science of Non-Equilibrium States of Modified Surface, Sumy State University, Sumy 2012. 
[5] A.D. Pogrebnjak, V.M. Beresnev, in Nanocomposites - New Trends and Developments, Eds. F. Ebrahimi, InTech, Rijeka 2012, p. 123, Ch. 6.

[6] J. Musil, Surf. Coat. Technol. 125, 322 (2000).

[7] A.D. Pogrebnjak, A.P. Shpak, V.M. Beresnev, D.A. Kolesnikov, Yu.A. Kunitsky, O.V. Sobol, V.V. Uglov, F.F. Komarov, A.P. Shypylenko, A.A. Demyanenko, V.S. Baidak, V.V. Grudnitskii, J. Nanosci. Nanotechnol. 12, 9213 (2012).

[8] A.V. Khomenko, Phys. Lett. A 329, 140 (2004).

[9] A.V. Larkin, A.K. Fedotov, J.A. Fedotova, T.N. Koltunowicz, P. Zhukowski, Mater. Sci.Poland 30, 75 (2012).

[10] A.D. Pogrebnjak, V.M. Beresnev, M.V. Il'yashenko, D.A. Kolesnikov, A.P. Shypylenko, A.Sh. Kaverina, N.K. Erdybaeva, V.V. Kosyak, P.V. Zukovski, F.F. Komarov, V.V. Grudnitskii, Ceram. Eng. Sci. Proc. 32, 69 (2011).
[11] A.D. Pogrebnjak, V.M. Beresnev, A.A. Demianenko, V.S. Baidak, F.F. Komarov, M.V. Kaverin N.A. Makhmudov, D.A. Kolesnikov, Phys. Solid State 54, 1882 (2012).

[12] A.D. Pogrebnjak, J. Nanomater. 2013, 780125 (2013).

[13] A.D. Pogrebnjak, O.V. Sobol, V.M. Beresnev, O.V. Sobol, V.M. Beresnev, P.V. Turbin, G.V. Kirik, N.A. Makhmudov, M.V. Il'yashenko, A.P. Shypylenko, M.V. Kaverin, M.Yu. Tashmetov, A.V. Pshyk, Nanostruct. Mater. Nanotechnol. IV: Ceram. Eng. Sci. Proc. 31, 127 (2010).

[14] A.V. Khomenko, N.V. Prodanov, Condens. Matter Phys. 11, 615 (2008).

[15] A.D. Pogrebnjak, S.N. Bratushka, V.M. Beresnev, N. Levintant-Zayonts, Russ. Chem. Rev. 82, 1135 (2013). 